coral would be found. Dr. Wayland Vaughan and Dr. J. E. Hoffmeister agree as to the age of the corals. The latter writes: "Most of the fragments seem to belong to Porites, two to Acropora, two to Pavona and two to Pocillopora. The Pavona is of the same type as $P$. duerdeni, Vaughan, or $P$. maldivensis (Gardiner), which are common in the Pacific of to-day. As Dr. Vaughan has said, there is nothing in this collection which might lead one to suspect that they are older than Pleistocene." He adds that among a collection of recent corals, made by Prof. Setchell, from the barrier reef off Papeete Harbour, he can find none common to the Tataa fauna.

Only one-third of the Tataa cone now remains, but it is clear from the attitude of the bedding that the original vent lies beneath the lagoon, and that the outer edge of the cone formerly extended on to the site of the present barrier reef. The denudation of the cone must have occurred before the rise to the surface of the barrier reef, since it cannot have been effected by lagoon currents alone. Moreover, the trend of the barrier reef ignores the original outlines of the cone.

At the exposed base of the cone, that is, at the edge of the lagoon, the tuffs lie either horizontally or roll at low angles, and in places, for a few inches above water-level, they show current-bedding. At higher levels the dips of the tuffs increase to $30^{\circ}$ away from the lagoon. It seems, therefore, that the basal tuffs were laid down at sea-level. From the foregoing it appears that since the formation of the Tataa cone the growth of the barrier reef in this part of Tahiti has been unaccompanied by any subsidence of the land relative to sea-level. Unfortunately, there seems to be no evidence as to the depth from which the reef grew during this period.

Geological Department,

Imperial College of Science, South Kensington, S.W.7 Oct. 21 .

\section{Science and Parliament.}

IT must be gratifying to all readers of NATURE to learn from the leading article in the issue of Oct. 26 that science will now have a group of members of the House of Commons who will, to some extent, look after the interests of the country in matters where science is concerned. This is due to the secretary of the Association of Scientific Workers, a body which is devoted to furthering the interests and usefulness of all who are engaged in scientific work. There is, so far as I know, no other body with the same aims; at least none which represents all branches of science. I say all branches of science because it can scarcely be said to represent-unless it be vicariously - all scientific workers, as its numbers are small compared with the great number of possible members. Those who know of its work realise that in its brief existence it has done a great deal to forward the interests of science. The increase in the Treasury grant for scientific publications was obtained through the efforts of this body, which has also done much useful work of a kind that cannot well be made public.

The membership of the Association of Scientific Workers has never been large, although it has always been representative. Now that it has in a definite way, as stated in the leading article in Nature, become actively connected with the Parliamentary Committee, those scientific workers who have hitherto refrained from joining would do well to consider if the time has not come when they should do so. Certainly, if science is to become powerful in Great
Britain, it will be necessary for all its votaries to band together in support of the only organisation which seems likely to be able to bring this about. If this is not done, the work will be crippled for want of funds. It cannot be expected that the British Science Guild and the British Association will be able or willing to subsidise the Association, and the present membership is insufficient to provide the necessary funds. A largely increased membership is needed, not only for this purpose but also that all shades of opinion and all groups of workers may contribute their quota to the coherent expression of the aims of British science and to the setting forth of its willingness and ability to assist in guiding the destinies of the Empire.

Teddington, Oct. 26.

\section{Properties of the Electron.}

It has been shown by me (Phil. Mag., 7, p. 493 ; 1909) that some of the main difficulties of the Bohr atom disappear if the electron possesses the property that it absorbs radiant energy during its motion, which induces a decrease of its electrical field, and under certain conditions ejects again the energy as radiation. A deduction of these properties was given based on thermodynamics and kinetic theory, which will be further elaborated in subsequent papers. The results may also be obtained in other ways, one of which will be pointed out here.

Suppose that an electron gas kept at constant temperature is subjected to a powerful magnetic field. The path of each electron will now possess greater curvature than before, resulting in an increased transformation of its kinetic energy into radiant energy, due to the acceleration it undergoes. A limiting case is that the concentration of the electrons is so small that in most cases they pass clear across the chamber. Thus the kinetic energy of the electrons will continually decrease. But this is manifestly an absurd result. Hence each electron will, on the average, recover its velocity during collision. This can take place only at the expense of the surrounding radiant energy, since the kinetic energy lost took this form. If radiation has the orthodox form, namely, that it consists of continuous electromagnetic waves, the electron can recoup the lost energy only by the gradual absorption of radiation which is stored up as internal energy. Since the emission of radiation due to the acceleration of the electron depends on the curvature of its path, the rate of absorption of radiant energy will similarly be dependent. The increase in velocity during a collision of the electron can be produced only by an increase in its field during the process, its internal energy supplying the necessary energy. Hence its field decreased during its mean free path.

Union College,

Schenectady, N.Y., U.S.A.

\section{Distribution of Medical Works.}

WE have been so much struck with the justice of the reviewer's comments in NATURE of Oct. 26 upon the limitation of the sale of Dr. Van de Velde's book, "Ideal Marriage", that we have decided for the future to sell it, not only to members of the medical profession, but also to biologists and other men of science, psychologists, sociologists, and representatives of scientific education and research.

\section{William Heinemann (Medical Books) Lti.} J. H. A. Elliot, Managing Director.

No. 3132, VoL. 124] 